\title{
Improving the Quality of Mixed Recycled Coarse Aggregates from Construction and Demolition Waste Using Heavy Media Separation with $\mathrm{Fe}_{3} \mathrm{O}_{4}$ Suspension
}

\author{
Heonchan Kang ${ }^{1}$ and Seong-Hoon Kee ${ }^{2}$ \\ ${ }^{1}$ Department of Energy, Minerals and Resources Engineering, Dong-A University, 37 Nakdong-Daero 550Beon-gil, Saha-gu, \\ Busan 604-714, Republic of Korea \\ ${ }^{2}$ Department of Architectural Engineering, Dong-A University, 37 Nakdong-Daero 550Beon-gil, Saha-gu, \\ Busan 604-714, Republic of Korea
}

Correspondence should be addressed to Seong-Hoon Kee; shkee@dau.ac.kr

Received 6 July 2016; Revised 8 November 2016; Accepted 9 November 2016; Published 2 January 2017

Academic Editor: Carlo Santulli

Copyright (C) 2017 H. Kang and S.-H. Kee. This is an open access article distributed under the Creative Commons Attribution License, which permits unrestricted use, distribution, and reproduction in any medium, provided the original work is properly cited.

\begin{abstract}
The primary objectives of this study are to investigate the feasibility of a heavy media separation process with magnetite $\left(\mathrm{Fe}_{3} \mathrm{O}_{4}\right)$ suspension for upgrading the quality of mixed recycled coarse aggregates from construction and demolition waste (CDW) in Korea and to determine a range of effective operating density of $\mathrm{Fe}_{3} \mathrm{O}_{4}$ suspension for producing high-quality RCA acceptable to structural concrete applications. For the purposes, six $200 \mathrm{~kg}$ recycled coarse aggregates (RCAs) samples were collected from a conventional recycling plant in Korea. Subsequently, the samples were processed by a heavy media separation process $\mathrm{using} \mathrm{Fe}_{3} \mathrm{O}_{4}$ suspensions with various densities from $2.65 \mathrm{~g} / \mathrm{cm}^{3}$ to $2.40 \mathrm{~g} / \mathrm{cm}^{3}$ with an interval of $0.05 \mathrm{~g} / \mathrm{cm}^{3}$. Next, a series of tests was performed in the laboratory to evaluate properties of finished sink and float products from the HMS processes, including oven-dry density, absorption capacity, and physical durability. Furthermore, compressive strength of concrete cylinders (150 mm by $300 \mathrm{~mm}) \mathrm{made}$ of the finished sink products from $\mathrm{Fe}_{3} \mathrm{O}_{4}$ suspensions with three different densities $\left(2.4,2.5\right.$, and $\left.2.6 \mathrm{~g} / \mathrm{cm}^{3}\right)$ was tested in this study. As a result, it was demonstrated that the HMS process using $\mathrm{Fe}_{3} \mathrm{O}_{4}$ suspension with a density ranging between 2.40 and $2.65 \mathrm{~g} / \mathrm{cm}^{3}$ was effective for upgrading mixed CDW RCAs in Korea to high-quality RCAs acceptable for structural concrete applications.
\end{abstract}

\section{Introduction}

It has been demonstrated that quality of the recycled concrete aggregate depends on the content of the porous and cement mortar attached to the recycled coarse aggregate (RCA) [1]. The presence of the weak phase results in lower density and higher water absorption of RCA than natural coarse aggregate (NCA), which unfavorably affects the properties of fresh and hardened concrete [2]. For example, concrete made of RCA may delay setting time and need more water for the same workability as normal concrete. Furthermore, concrete made of RCA has relatively low mechanical properties (e.g., density, compressive strength, and modulus of elasticity) and higher permeability and higher carbonation rate and greater reinforced steel corrosion characteristics compared to normal concrete. Therefore, many national standards and international recommendations [3-9] limit the use of RCA in concrete structures according to the density and absorption capacity of RCA (see Table 1).

A number of researchers have proposed various mineral dressing operations for improving the quality of RCA by removing the attached cement paste. Nagataki et al. [10] observed that increasing the number of crushing stages is effective for reducing the attached mortar content and damage in RCA. Tam et al. [11] demonstrated that attached cement paste can be significantly removed from RCA through acid treatment. Shima et al. [12] studied thermal treatments combined with abrasion for improving the purity of RCA. An electrical impulse method [13, 14] was studied as an innovative tool for improving the quality of RCA. Bru et al. 
TABLE 1: Minimum criteria for recycled aggregate for various applications.

\begin{tabular}{|c|c|c|c|c|}
\hline $\begin{array}{l}\text { National standard or } \\
\text { recommendation }\end{array}$ & RCA type & $\begin{array}{l}\text { Absolute dry density } \\
\left(\mathrm{g} / \mathrm{cm}^{3}\right)\end{array}$ & $\begin{array}{c}\text { Absorption } \\
\text { capacity (\%) }\end{array}$ & Note \\
\hline \multirow{2}{*}{ AS 1141.6.2 [4] } & Class $1 \mathrm{~A}$ & $\geq 2.1$ & $\leq 6$ & $\begin{array}{l}\text { Well graded RCA W/brick content < } \\
0.5 \%\end{array}$ \\
\hline & Class $1 \mathrm{~B}$ & $\geq 1.8$ & $\leq 8$ & $\begin{array}{l}\text { Class 1A RAC mixed W/crushed brick } \\
<30 \%\end{array}$ \\
\hline \multirow{4}{*}{ DIN 4226-100 [6] } & Type 1 & $\geq 2.0$ & $\leq 10$ & Concrete chipping + crusher sand \\
\hline & Type 2 & $\geq 2.0$ & $\leq 15$ & Construction shipping + crusher sand \\
\hline & Type 3 & $\geq 1.8$ & $\leq 20$ & Masonry chipping + crusher sand \\
\hline & Type 4 & $\geq 1.5$ & No limit & Mixed chippings + crusher sand \\
\hline \multirow{9}{*}{$\begin{array}{l}\text { JIS A5021, 5022, and } \\
5033[7-9]\end{array}$} & Class H & & & $\begin{array}{l}\text { No limitations and segment for } \\
\text { concrete and structures W/nominal } \\
\text { strength } 45 \mathrm{MPa} \text { or less }\end{array}$ \\
\hline & Coarse & $\geq 2.5$ & $\leq 3$ & \\
\hline & Fine & $\geq 2.5$ & $\leq 3.5$ & \\
\hline & Class M & & & $\begin{array}{l}\text { Members not subjected to drying or } \\
\text { freeze-thawing action }\end{array}$ \\
\hline & Coarse & $\geq 2.3$ & $\leq 5$ & \\
\hline & Fine & $\geq 2.2$ & $\leq 7$ & \\
\hline & Class L & & & $\begin{array}{l}\text { Backfill concrete, blinding concrete, } \\
\text { and concrete filled in steel tubes }\end{array}$ \\
\hline & Coarse & No limit & $\leq 7$ & \\
\hline & Fine & No limit & $\leq 13$ & \\
\hline \multirow{2}{*}{ KS F 2573 [5] } & Coarse & $\geq 2.5$ & $\leq 3$ & Members W/a nominal strength \\
\hline & Fine & $\geq 2.2$ & $\leq 5$ & $27 \mathrm{MPa}$ or less \\
\hline \multirow{3}{*}{ RILEM [3] } & Type 1 & $\geq 1.5$ & $\leq 20$ & Aggregates from masonry rubble \\
\hline & Type 2 & $\geq 2.0$ & $\leq 10$ & Aggregates from concrete rubble \\
\hline & Type 3 & $\geq 2.5$ & $\leq 3$ & $\begin{array}{l}\text { Natural }(\geq 80 \%)+\text { recycled }(\leq 20 \%) \\
\text { aggregate }\end{array}$ \\
\hline
\end{tabular}

developed a microwave-assisted recycling process for the recovery of high-quality aggregates from concrete waste [15]. Recently, a near-infrared sorting technology was constructed for upgrading the quality of mixed recycled aggregates from CDW [16]. However, so far, there has been no widely accepted method in the market, especially for improving RCA in mixed CDW which are composed of concrete, asphalt concrete, ceramic tile, red brick, wood, and plastic $[17,18]$.

Heavy media separation (HMS) method has been demonstrated to be effective for separating high-quality RCA from mixed CDW by means of sink-float separation in a heavy liquid. The heavy liquid recommended in ASTM C123 [19] includes zinc chloride $\left(\mathrm{ZnCl}_{2}\right)$ in water, 1,1,1,2tetrabromoethane $\left(\mathrm{C}_{2} \mathrm{H}_{2} \mathrm{Br}_{4}\right)$, and zinc bromide $\left(\mathrm{ZnBr}_{2}\right)$ in water. Augulo et al. [20] used $\mathrm{ZnCl}_{2}$ water solution with a density of $1.9 \mathrm{~g} / \mathrm{cm}^{3}$ and bromoform $\left(\mathrm{CHBr}_{3}\right)$ ethylic alcohol solution with densities of 2.2 and $2.5 \mathrm{~g} / \mathrm{cm}^{3}$ for categorizing Brazilian CDW in the order of density in the laboratory. Lee et al. [21] sorted RCA in the order of the density from 2.16 to $2.69 \mathrm{~g} / \mathrm{cm}^{3}$ through a HMS process using $\mathrm{C}_{2} \mathrm{H}_{2} \mathrm{Br}_{4}$ methyl alcohol solution with varying densities in the laboratory. According to ASTM C123 [19], $\mathrm{ZnCl}_{2}$ water solution and
$\mathrm{ZnBr}_{2}$ water solution are only recommended for specific gravity up to about 2.0 and 2.4, respectively; thus, they may be inappropriate for separating high-quality RCA for structural concrete, such as Grade I in KS F 2573 [5], Class $\mathrm{H}$ in JIS A 5021 [7], and Type 3 in RILEM [3]. In contrast, $\mathrm{CHBr}_{3}$ and $\mathrm{C}_{2} \mathrm{H}_{2} \mathrm{Br}_{4}$ have specific gravities of 2.89 and 2.95, respectively. Consequently, those are useful for separating high-quality RCA with a density equal to or higher than $2.5 \mathrm{~g} / \mathrm{cm}^{3}$. However, there are several practical limitations to using $\mathrm{CHBr}_{3}$ and $\mathrm{C}_{2} \mathrm{H}_{2} \mathrm{Br}_{4}$ solution as follows: (1) prohibitively high cost, (2) flammability, (3) toxicity, and (4) solubility of organic materials such as asphalt concrete. In contrast, Angulo et al. [17] used a pseudoheavy medium using ferrosilicon-water suspension to classify mixed CDW aggregate by a HMS process. In the study, they investigated the effect of the medium density on the porosity of the resulting RCA and its impact on the mechanical properties of concrete in the laboratory. Ferrosilicon power with a gravity specific of $6.7 \sim 7.1$ containing 13 16\% silicon is commonly used for the heavy media separation process in the mine industry [22]. However, it is still expensive to be used for producing recycled coarse aggregates for the construction industry. 


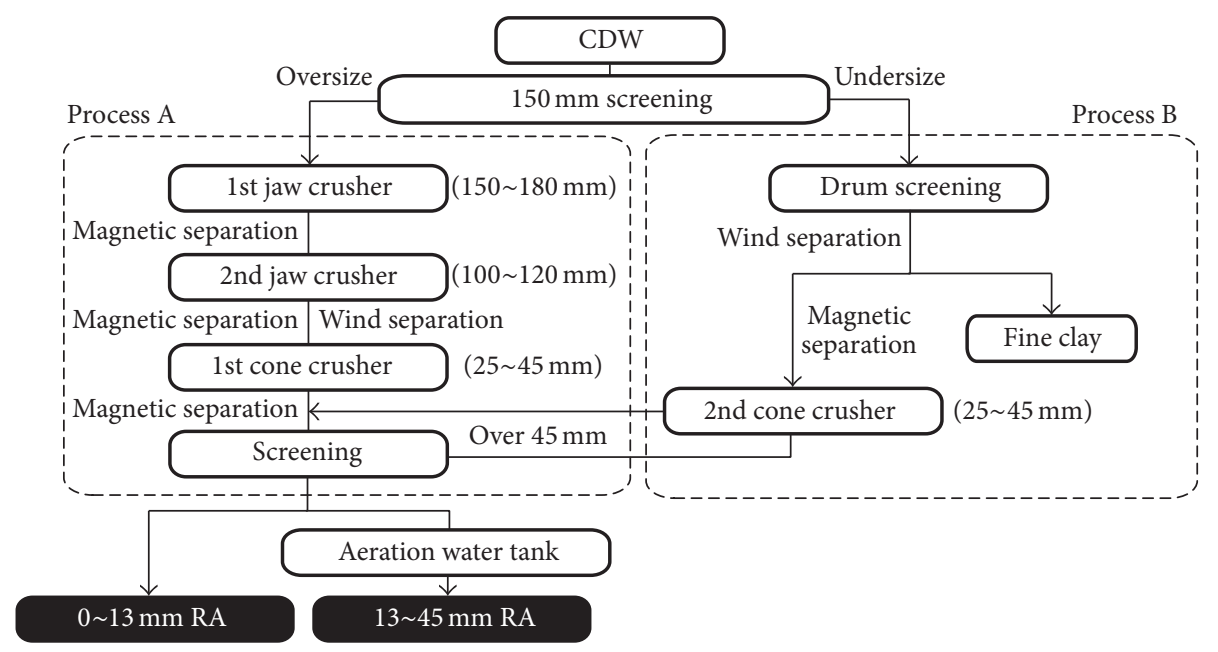

FIGURE 1: Production process of recycled aggregates in a recycling plant.

In this study, the authors developed a prototype HMS system with $\mathrm{Fe}_{3} \mathrm{O}_{4}$-water suspension as a cost-effective pseudoheavy medium in practice. $\mathrm{A} \mathrm{Fe}_{3} \mathrm{O}_{4}$ suspension is commonly used as a medium solid in coal and iron industries due to its cost-effectiveness, high density, resistance to abrasion and corrosion, and recoverability for reuse. The main objectives of this study are to investigate the feasibility of a heavy media separation process with $\mathrm{Fe}_{3} \mathrm{O}_{4}$ suspension for upgrading the quality of mixed recycled coarse aggregates from construction and demolition waste (CDW) in Korea and to determine a range of effective operating density of $\mathrm{Fe}_{3} \mathrm{O}_{4}$ suspension in the HMS process for producing highquality RCA acceptable to structural concrete applications.

\section{Heavy Media Separation (HMS) Using Magnetite $\left(\mathrm{Fe}_{3} \mathrm{O}_{4}\right)$ Suspension}

2.1. Mixed Recycled Coarse Aggregates from CDW in Korea: Input Material in HMS. The raw material input to the HMS process in this study is mixed recycled coarse aggregates from CDW (or referred to as CDW RCA) in Korea, which were produced by a series of crushing and screening processes in a conventional recycling plant in Korea (see Figure 1). The CDW RCAs in Korea are generally composed of aggregates with various amounts of attached mortar, occupying about $90 \%$ of the volume, and foreign substances such as ceramic tile, asphalt concrete, red brick, mortar, wood chip, and plastic, occupying about $10 \%$ of the volume (see Figure 2). Those foreign substances have lower density and higher absorption capacity than natural aggregates for concrete. Average density and absorption capacity of various foreign substances in common Korean CDW RCA is summarized in Table 2. It has been known that the oven-dry (OD) density of typical Korean CDW RCAs ranges between $1.95 \mathrm{~g} / \mathrm{cm}^{3}$ and $2.23 \mathrm{~g} / \mathrm{cm}^{3}$, with an average of about $2.15 \mathrm{~g} / \mathrm{cm}^{3}$, and the absorption capacity ranges between $6.5 \%$ and $10.3 \%$, with an average of about $7.75 \%$. Obviously, the values do not satisfy the requirement for high-quality recycled aggregates
TABLE 2: Summary of oven-dry density and absorption capacity of typical materials in mixed CDW recycled aggregates produced by recycling plants in Korea.

\begin{tabular}{lcc}
\hline & $\begin{array}{c}\text { Oven-dry density } \\
\left(\mathrm{g} / \mathrm{cm}^{3}\right)\end{array}$ & $\begin{array}{c}\text { Absorption capacity } \\
(\%)\end{array}$ \\
\hline $\begin{array}{l}\text { Recycled aggregates } \\
\text { for concrete }\end{array}$ & $2.56 \sim 2.64$ & $2.05 \sim 2.60$ \\
Asphalt concrete & $2.22 \sim 2.27$ & $2.07 \sim 2.97$ \\
Ceramic tile & $2.02 \sim 2.10$ & $5.13 \sim 6.21$ \\
Mortar & $1.92 \sim 1.98$ & $9.26 \sim 9.89$ \\
Red brick & $1.90 \sim 1.94$ & $9.66 \sim 9.96$ \\
\hline
\end{tabular}

for structural concrete, such as Grade I in KS F 2573 [5], Class $\mathrm{H}$ in JIS A 5021 [7], and Type 3 in RILEM [3].

2.2. Magnetite $\left(\mathrm{Fe}_{3} \mathrm{O}_{4}\right)$ Suspension in HMS. Magnetite concentrate powders produced by a beneficiation plant in China were used as the medium solid for the HMS process. The Chinese magnetite concentrate has a dry density of $4.75 \mathrm{~g} / \mathrm{cm}^{3}$, and the particle size is mostly between 45 and $75 \mu \mathrm{m}$ with an average particle size of $54.9 \mu \mathrm{m}$. However, it contains some forms of impurities such as phosphorus, aluminum, titanium, and silica, which may lower dry density compared to that of pure magnetite $\left(5.18 \mathrm{~g} / \mathrm{cm}^{3}\right)$.

The $\mathrm{Fe}_{3} \mathrm{O}_{4}$ suspension with a specific density was prepared by diluting the magnetite concentrate powers with water. The mass of magnetite $M_{M}$ required to produce a heavy medium with the specified density $\rho_{S}$ and mass $M_{S}$ was determined using the following equation:

$$
M_{M}=\frac{M_{S}\left(\rho_{S}-1\right) \rho_{M}}{\rho_{S}\left(\rho_{M}-1\right)},
$$

where $\rho_{M}$ is the density of magnetite concentrate powder and $\rho_{\mathrm{S}}$ is the target density of $\mathrm{Fe}_{3} \mathrm{O}_{4}$ suspension. For example, the $\mathrm{Fe}_{3} \mathrm{O}_{4}$ suspension with a target density of $2.6 \mathrm{~g} / \mathrm{cm}^{3}$ needed $78.63 \mathrm{~g}$ of the magnetite concentrate in a $100 \mathrm{~g}$ dense medium, 


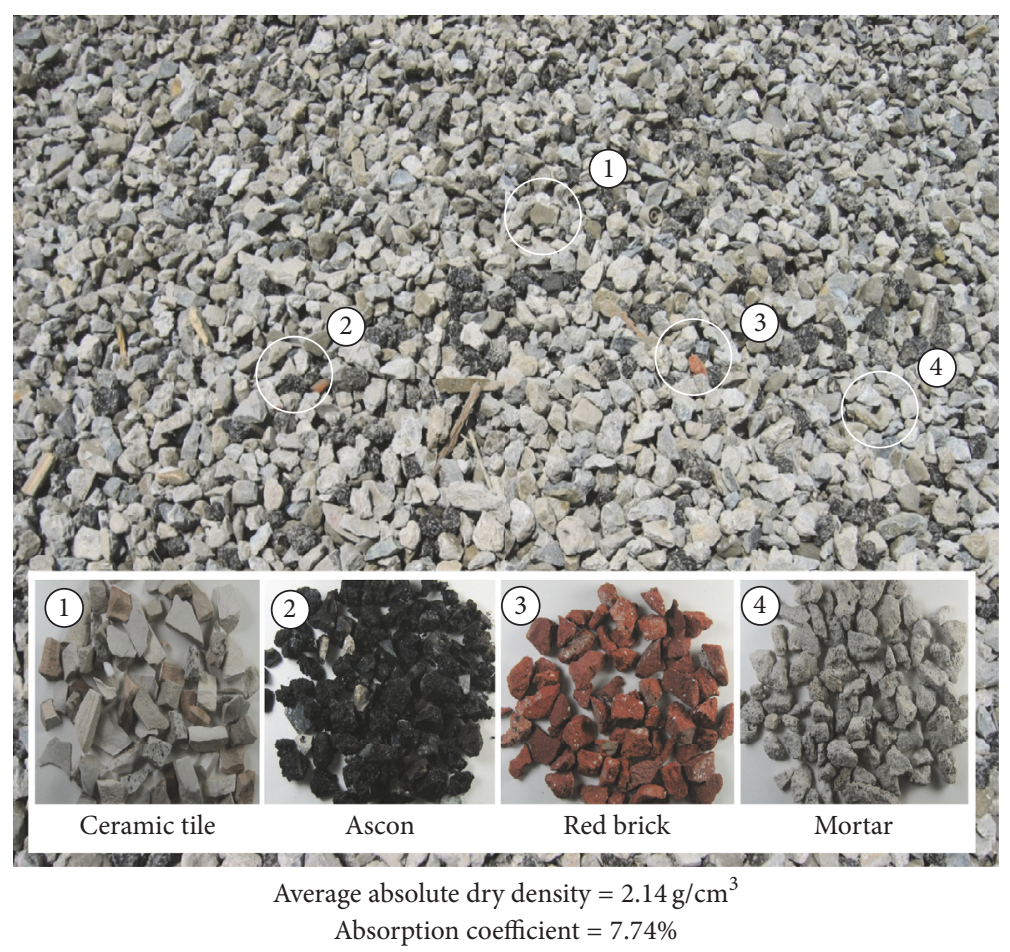

FIGURE 2: Recycled aggregates from construction demolition waste (CDW) produced by a conventional recycling plant in Korea.

which occupies approximately $43 \%$ of the total volume of the dense medium.

In this study the target density of the magnetite suspension ranges between $2.40 \mathrm{~g} / \mathrm{cm}^{3}$ and $2.65 \mathrm{~g} / \mathrm{cm}^{3}$ with an interval of $0.05 \mathrm{~g} / \mathrm{cm}^{3}$. The upper limit of target density $\left(2.65 \mathrm{~g} / \mathrm{cm}^{3}\right)$ was determined from an observation in the laboratory that the viscosity of the $\mathrm{Fe}_{3} \mathrm{O}_{4}$ suspension suddenly increased when the density of the magnetite suspension exceeded the threshold value and significantly decreased workability and efficiency of the HMS process.

2.3. Prototype System for $\mathrm{HMS}$ Using $\mathrm{Fe}_{3} \mathrm{O}_{4}$ Suspension. A prototype HMS system was developed by a research team in Dong-A University for producing high-quality RCA from mixed CDW RCAs. A flow chart of the prototype system is illustrated in Figure 3. In the HMS process, mixed CDW RCAs in Korea were first loaded to a vibration screen, and only particles smaller than $50 \mathrm{~mm}$ were put into a separating machine (drum separator in this study; see Figure 4(a)) that contained $\mathrm{Fe}_{3} \mathrm{O}_{4}$ suspension with a certain target density. The drum separator is a heart of the HMS process, which automatically divides the input material into two groups. Consequently, particles with a higher density than $\mathrm{Fe}_{3} \mathrm{O}_{4}$ suspension sank, whereas those with a lower density floated (see Figure 4(b)). The sink particles were discharged at the bottom of the drum separator (see Figures 5(c) and 5(d)), and the float particles were transferred to the upper part of the rotating cylinder (see Figure 5(a)) and then emitted (see Figure 5(b)). Note that the drum separator was designed to revolve 5 cycles per a minute to maintain appropriate stability of medium in the HMS process. Both discharged particles became black due to the magnetite medium adhering to the surface of the products. The medium on the surface of the sink and float was rinsed away with distributed water spraying systems on vibration screens. Then, finished sink and float products are separately stacked in the yard.

In addition, the prototype HMS system includes treatment and circulation systems for recycling magnetite medium and water as to minimize the environmental impacts of using recycled aggregates. The magnetic medium circulates in the circuit to keep the medium density in the drum separator constant in a certain limit. Some magnetite media from the drum separator, attaching to the sink or float particles, were collected to the supply tank A (see Figure 6(b)). In contrast, the magnetite medium in rinsing water was recovered by two-stage magnetic separation process (see Figure 6). Nonmagnetic tailings and condensed magnetite are stored in tanks $B$ and $C$, respectively. The density of the medium in tank A was kept constant within certain limits by monitoring the medium density using a nuclear density gauge and automatically supplying the required amount of water and concentrated medium. Then, the magnetite medium with constant density is continuously supplied to the drum separator. It was observed that the two-stage magnetic separation process is very effective for recycling most of the magnetite with a magnetite loss of about $100 \mathrm{~g}$ per $1 \mathrm{~m}^{3}$ of input materials. In addition, an overflow from the heavy media slurry feed in tank $C$ is directed to the water tank after a treatment process in tank C. The heavy media slurry is condensed in a filter press, and clean water is supplied to rinsing water recirculating in the circuit (see Figure 6). 


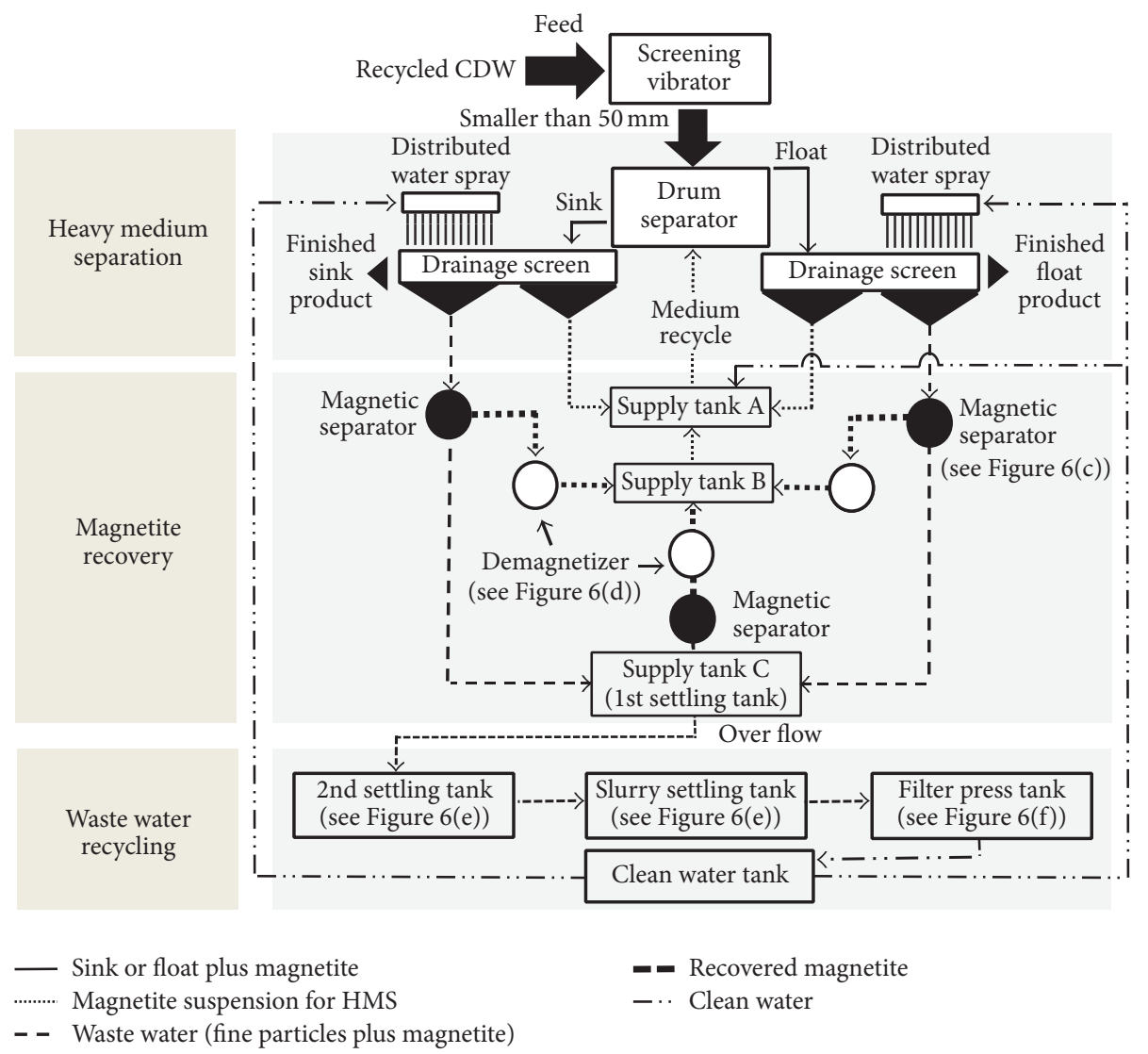

FIGURE 3: Illustration of the prototype heavy media separation system using $\mathrm{Fe}_{3} \mathrm{O}_{4}$ suspension in this study.

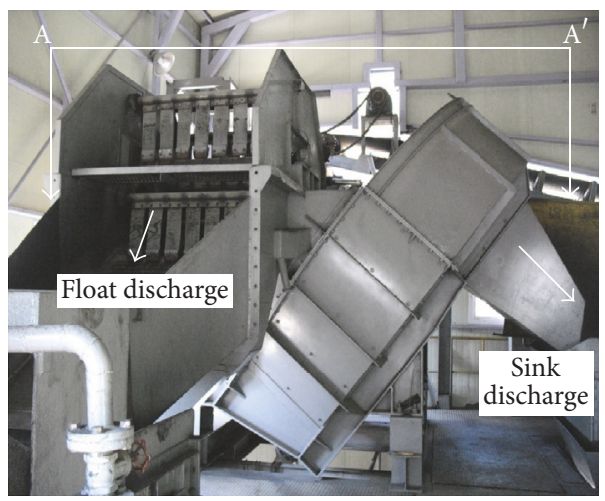

(a)

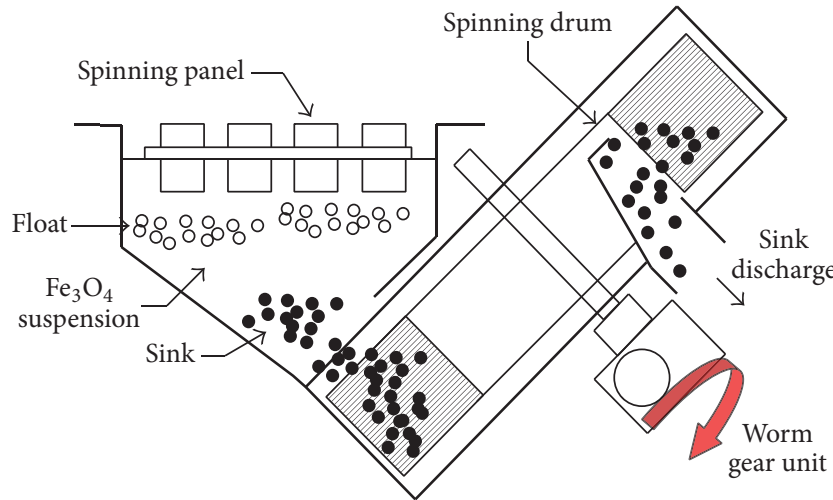

(b)

Figure 4: Prototype equipment of dense medium separation process using $\mathrm{Fe}_{3} \mathrm{O}_{4}$ suspension (a) and the sectional view A- $\mathrm{A}^{\prime}$ in Figure 4(a).

The investment cost for construction of the prototype HES system was approximately 1.5 million US \$, which includes construction of steel frames (237K US \$), heavy medium separation system (382K US \$), magnetite recycling system (276K US \$), water disposal plant (216K US $\$$ ), and thickening tank and dewatering facility (245K US $\$)$. Based on these investment costs, the annual capital costs are about $225 \mathrm{~K}$ US $\$$ based a depreciation time of ten years and 5\% interest rate. Moreover, annual operation costs are estimated to be about $130 \mathrm{~K}$ US $\$$ on the assumption of an operating time of $2400 \mathrm{hr} /$ year, medium wear expenses of $16 \mathrm{~K}$ US \$, energy costs of $38 \mathrm{~K}$ US \$, and maintenance and insurance costs of $2.5 \%$ and $1.0 \%$, respectively. Assuming a treatment capacity of $150 \mathrm{ton} / \mathrm{hr}$, the resulting processing cost is about 0.98 US $\$ /$ ton of processed material. 


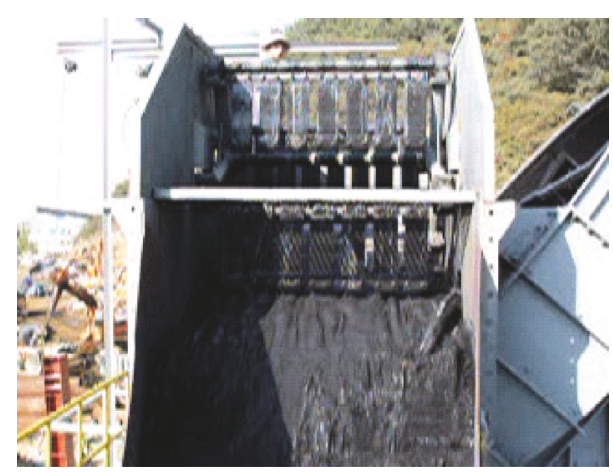

(a)

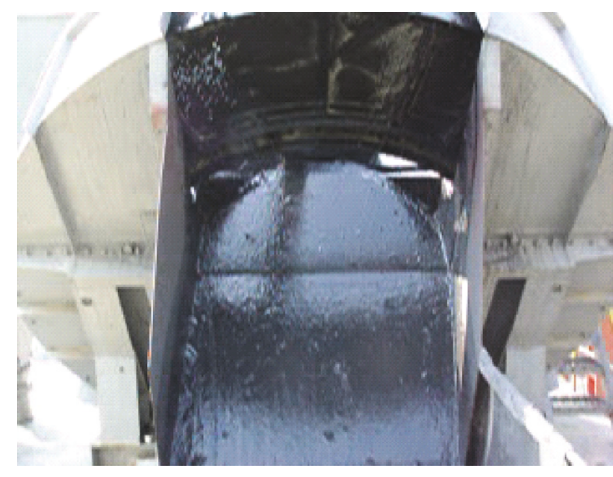

(c)

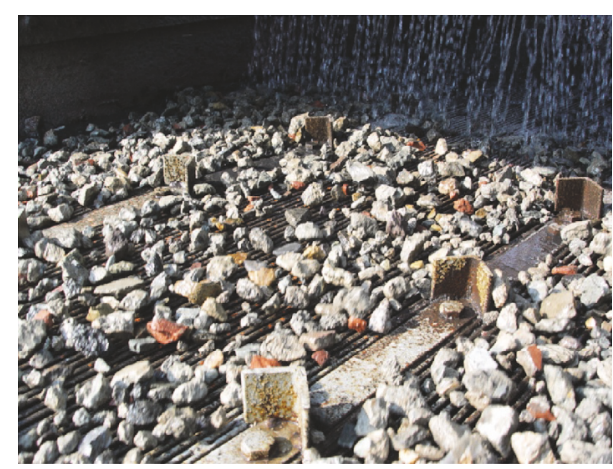

(b)

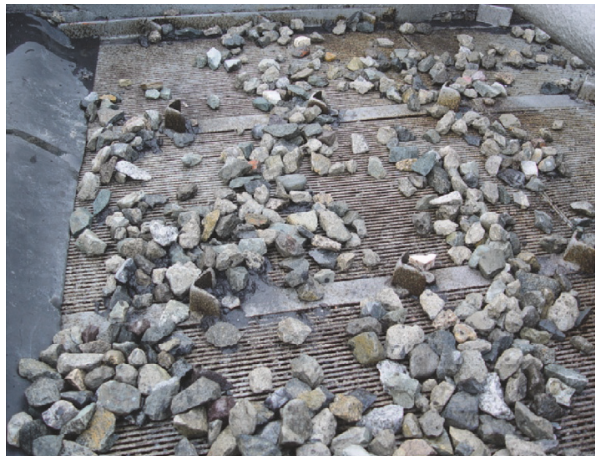

(d)

FIGURE 5: Sink and float particles after the heavy media separation process: (a) outlet of float particles in the drum separator, (b) finished float product after washing, (c) outlet of sink particles in the drum separator, and (d) finished sink product after washing.

\section{Test Program}

3.1. Density and Absorption Capacity of RCAs. Test samples used in this study were five $200 \mathrm{~kg}$ RCAs with a size distribution of 13 45 mm, which were collected from a conventional CDW recycling plant in Korea (see Figure 2). The six RCA samples were processed by using the HMS system with six different densities of $\mathrm{Fe}_{3} \mathrm{O}_{4}$ suspension, ranging between $2.65 \mathrm{~g} / \mathrm{cm}^{3}$ and $2.40 \mathrm{~g} / \mathrm{cm}^{3}$ with an interval of $0.05 \mathrm{~g} / \mathrm{cm}^{3}$.

After each separation process, a series of tests were performed to evaluate the properties of the finished sink and float product such as OD density and absorption capacity. Then, the values were correlated with the density of $\mathrm{Fe}_{3} \mathrm{O}_{4}$ suspension in the HMS process. The test results were used to investigate the effects of the medium density in the HMS process on the properties of the resulting product and to determine an optimum medium density in the HMS process.

The average density and absorption capacity of the RCAs in the OD condition were determined according to ASTM C128 [23].

$$
\rho_{\mathrm{OD}}=\frac{w_{\mathrm{OD}}}{w_{\mathrm{displ}}} \times \rho_{\mathrm{water}}
$$

where $w_{\mathrm{OD}}$ is the weight of the recycled aggregate samples in the OD condition and $w_{\text {displ }}$ is the weight of water displacement measured from the RCA samples in the SSD condition $\left(w_{\text {displ }}=w_{\text {air }}-w_{\text {water }}\right.$, where $w_{\text {air }}$ and $w_{\text {water }}$ are the weight of RCA in the SSD condition measured in air and in water, resp.). In addition, the absorption capacity of the RCA samples was determined as follows:

$$
A=\frac{w_{\mathrm{SSD}}-w_{\mathrm{OD}}}{w_{\mathrm{OD}}} \times 100(\%)
$$

3.2. Measurements of Physical Durability of RCAs. In addition, a series of tests was performed to investigate the physical durability and the impurity contents of the sink and float produced by the HMS process using the six different densities of $\mathrm{Fe}_{3} \mathrm{O}_{4}$ suspension. For evaluating the physical durability of RCAs, the soundness test and wear resistance test were performed according to ASTM C88 and ASTM C535, respectively. In the soundness test, the resistance to disintegration by sulfates was evaluated by repeating immersion in saturated solution of sodium sulfate followed by oven drying. The weight loss after five cycles of tests was used as a means of the soundness of the RCAs subjected to weathering action in concrete. Furthermore, the wear resistance of processed RCAs was evaluated by using the Los Angeles test. Note that only large-size RCAs larger than $19 \mathrm{~mm}$ were considered in this study. The Los Angeles test involves ball milling the aggregate with steel balls for about 33.3 minutes with a rotation velocity of $30 \mathrm{r} / \mathrm{min}$, sieving the fine materials over a $1.7 \mathrm{~mm}$ (number 12) sieve, and measuring the mass loss. The weight loss after the Los Angeles test is used as a means of wear resistance. 


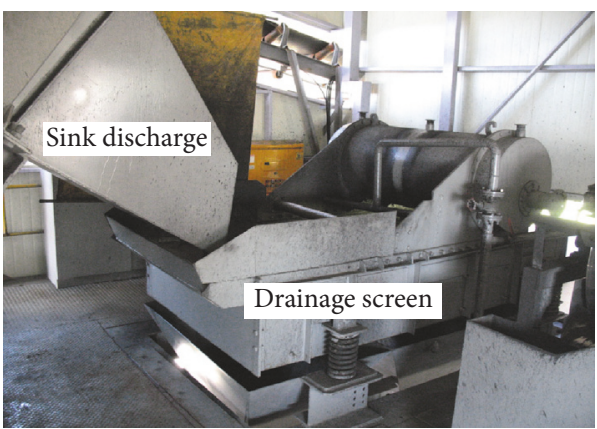

(a)

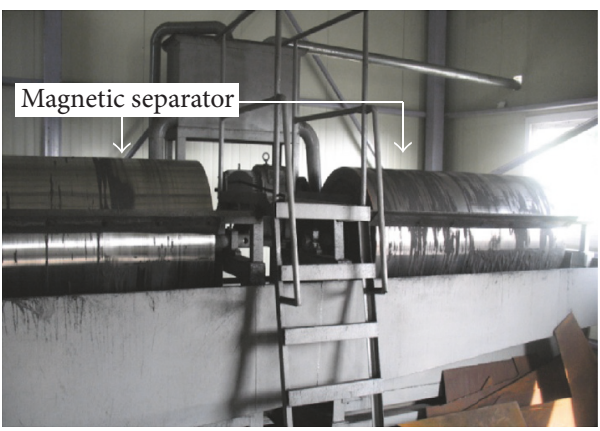

(c)

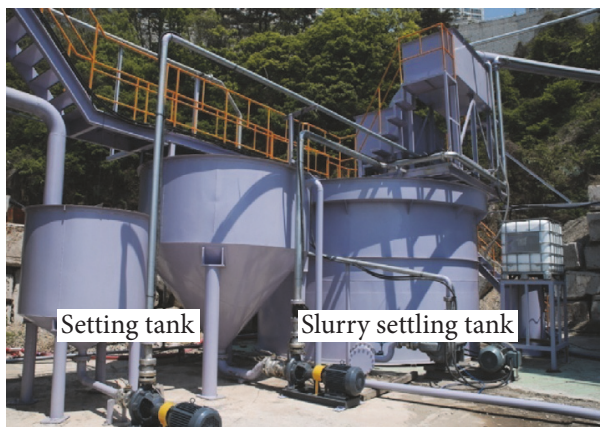

(e)

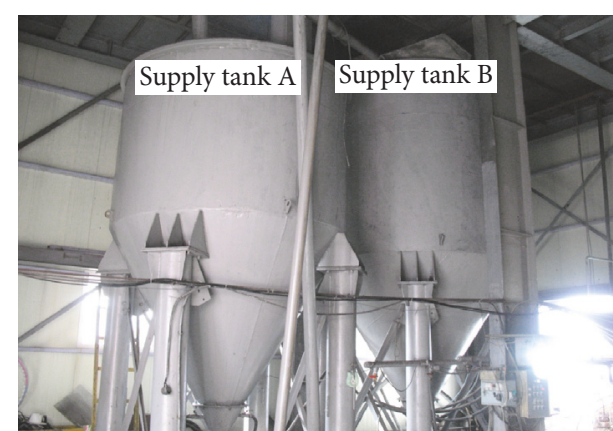

(b)

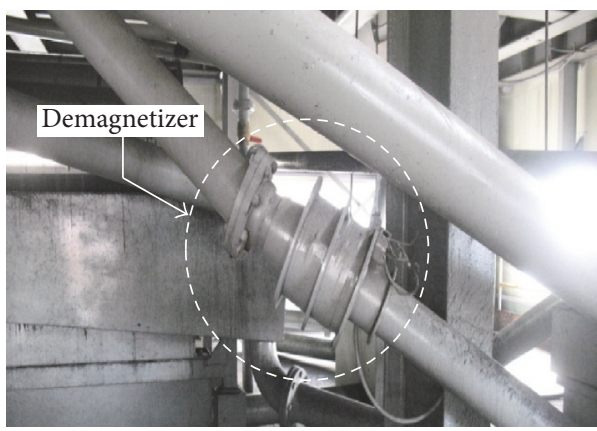

(d)

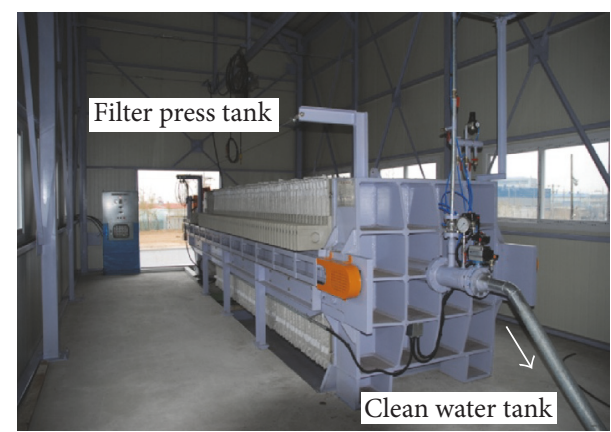

(f)

FIGURE 6: Pictures of the prototype HMS system in this study: (a) entrance of drainage screen, (b) supply tanks A and B, (c) magnetic separator, (d) demagnetizer, (e) slurry settling tank, and (f) filter press tank.

3.3. Compressive Strength of Concrete Made of RCAs. Compressive strength of concrete made of RCAs was performed to investigate the effect of processed RCAs on mechanical properties of hardened concrete. The concrete for compressive tests consists of type I Portland cement, river sand, and coarse aggregates obtained from five different sources. The concrete mixture proportions are summarized in Table 3. Coarse aggregates in concrete mix 1 used unprocessed RCA, and mixes 2,3 , and 4 used the sink product in the HMS process with the medium density of $2.45,2.55$, and $2.65 \mathrm{~kg} / \mathrm{cm}^{3}$, respectively, which is called RCA-2.45, RCA-2.55, and RCA2.65. In addition, NCAs were used for mix 5 . Total seventyfive concrete cylinders (fifteen for each concrete mix) were cast in 150 by $300 \mathrm{~mm}$ plastic molds according to ASTM C31 [24]. The cylinders were water-cured after being demolded on the next day. Uniaxial compressive test was conducted at 7,14 , and 28 days. The cylinders were ground at both ends before testing to remove any surface irregularities and to ensure that the ends were perpendicular to the sides of the specimen. Compressive strength of the cylinders was measured using a Universal Testing Machine (UTM) with a capacity of $1000 \mathrm{kN}$ according to ASTM C39-14 [25]. Tests were performed at a loading rate of approximately $0.25 \mathrm{MPa} / \mathrm{s}$.

\section{Results and Discussion}

4.1. OD Density and Absorption Capacity of Improved RCAs. Figure 7 is a plot representing the variations of OD density of finished float and sink products in the HMS processes as a density of $\mathrm{Fe}_{3} \mathrm{O}_{4}$ suspension ranging between $2.4 \mathrm{~g} / \mathrm{cm}^{3}$ and $2.65 \mathrm{~g} / \mathrm{cm}^{3}$. As expected, the density of the finished sink product is slightly higher than the target density of $\mathrm{Fe}_{3} \mathrm{O}_{4}$ suspension in a drum separator. The use of $\mathrm{Fe}_{3} \mathrm{O}_{4}$ suspension 


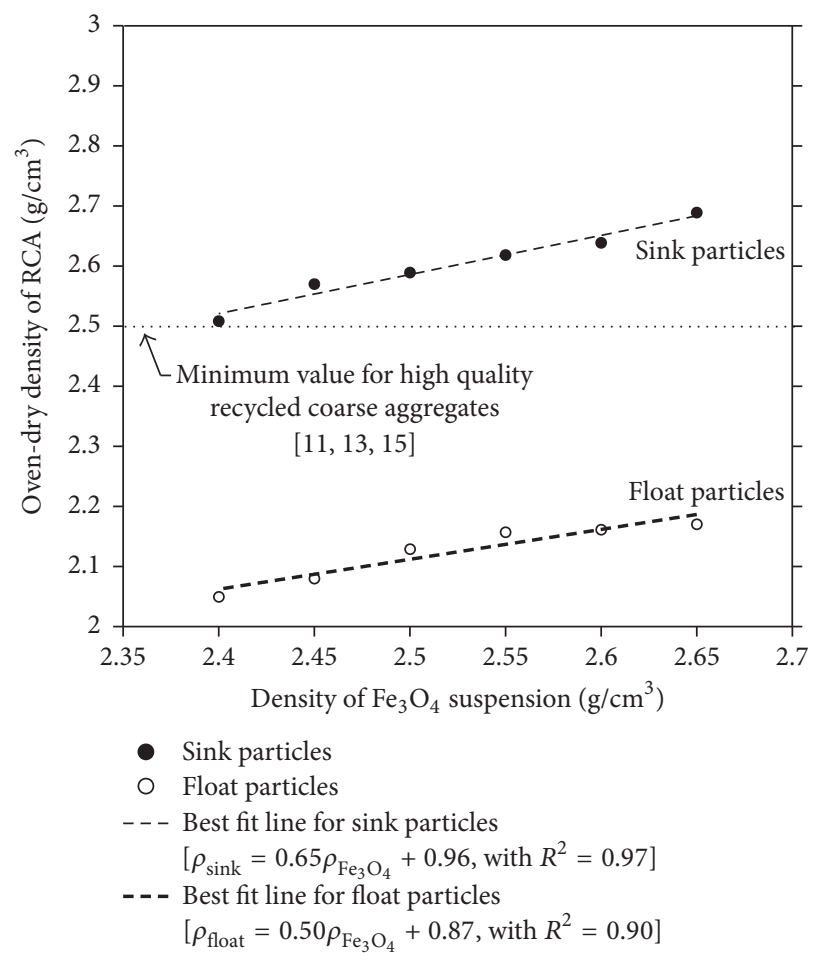

Figure 7: The variations of the oven-dry density of sink and float in the heavy medium separation process with a density of $\mathrm{Fe}_{3} \mathrm{O}_{4}$ suspension in the drum separator.

TABLE 3: Summary of mix proportions for compressive strength tests.

\begin{tabular}{|c|c|c|c|c|c|c|c|}
\hline \multirow{2}{*}{ Number } & \multirow{2}{*}{ Aggregate type } & \multirow{2}{*}{$\mathrm{W} / \mathrm{C}$} & \multirow{2}{*}{ S/a (\%) } & \multicolumn{4}{|c|}{ Unit weight $\left(\mathrm{kg} / \mathrm{m}^{3}\right)$} \\
\hline & & & & W & $\mathrm{C}$ & S & G \\
\hline 1 & RCA before HMS & 45.2 & 38 & 167 & 358 & 675 & 1027 \\
\hline 2 & RCA 2.45 & 45.9 & 37.8 & 162 & 353 & 670 & 1067 \\
\hline 3 & RCA 2.55 & 45.2 & 38 & 162 & 359 & 671 & 1067 \\
\hline 4 & RCA 2.65 & 46.6 & 38.7 & 167 & 358 & 678 & 1026 \\
\hline 5 & NCA & 45.0 & 38 & 162 & 358 & 670 & 1025 \\
\hline
\end{tabular}

Note: RCA-2.45, RCA after heavy media separation process with a magnetite medium density of $2.45 \mathrm{~kg} / \mathrm{cm}^{3} ; \mathrm{NCA}$, natural river coarse aggregates; W/C, water-to-cement ratio; S/a, sand-to-coarse aggregate ratio by weight; $\mathrm{W}$, water; $\mathrm{C}$, cement; S, sand; G, gravel.

with a density of $2.65 \mathrm{~g} / \mathrm{cm}^{3}$ produced sink particles with an average OD density of $2.69 \mathrm{~g} / \mathrm{cm}^{3}$, which is comparable to those of natural coarse aggregate (NCA). As the medium density decreases from $2.65 \mathrm{~g} / \mathrm{cm}^{3}$ to $2.4 \mathrm{~g} / \mathrm{cm}^{3}$, the OD density of sink particles decreases from $2.69 \mathrm{~g} / \mathrm{cm}^{3}$ to $2.51 \mathrm{~g} / \mathrm{cm}^{3}$, which are greater than the minimum criteria (i.e., $2.5 \mathrm{~g} / \mathrm{cm}^{3}$ ) for high-quality recycled aggregates for structural concrete applications (i.e., Class H in JIS [7], Type 3 in RILEM [3], and Grade I in KS [5]). An approximate equation that relates the density of the OD density of sink products in the HMS process $\left(\rho_{\text {sink }}\right)$ and the density of the $\mathrm{Fe}_{3} \mathrm{O}_{4}$ suspension in the drum separator $\left(\rho_{\mathrm{FE}_{3} \mathrm{O}_{4}}\right)$ is established by a linear regression analysis as follows:

$$
\rho_{\text {sink }}=0.65 \rho_{\mathrm{FE}_{3} \mathrm{O}_{4}}+0.96, \quad \text { with } R^{2}=0.97
$$

From (4), the minimum density of $\mathrm{Fe}_{3} \mathrm{O}_{4}$ suspension to produce RCA with a density of $2.5 \mathrm{~g} / \mathrm{cm}^{3}$ is calculated to be 2.369 .

In addition, the variations of absorption capacity of float and sink particles with $\mathrm{Fe}_{3} \mathrm{O}_{4}$ suspension in a drum separator during the HMS process are shown in Figure 8. Similar to OD density, the absorption capacity of sink particles tends to increase as the medium density increases from $2.4 \mathrm{~g} / \mathrm{cm}^{3}$ to $2.65 \mathrm{~g} / \mathrm{cm}^{3}$. Magnetite suspension with a density of $2.65 \mathrm{~g} / \mathrm{cm}^{3}$ resulted in finished sink product with an average absorption capacity of $1.88 \%$, which is as low as those of NCAs. As the density decreases from $2.65 \mathrm{~g} / \mathrm{cm}^{3}$ to $2.4 \mathrm{~g} / \mathrm{cm}^{3}$, the absorption capacity increases from $1.88 \%$ to $2.69 \%$, all of which are less than the maximum value for the high-quality recycled aggregates (i.e., 3\%) for structural concrete. It was observed that the decreasing rate of the 


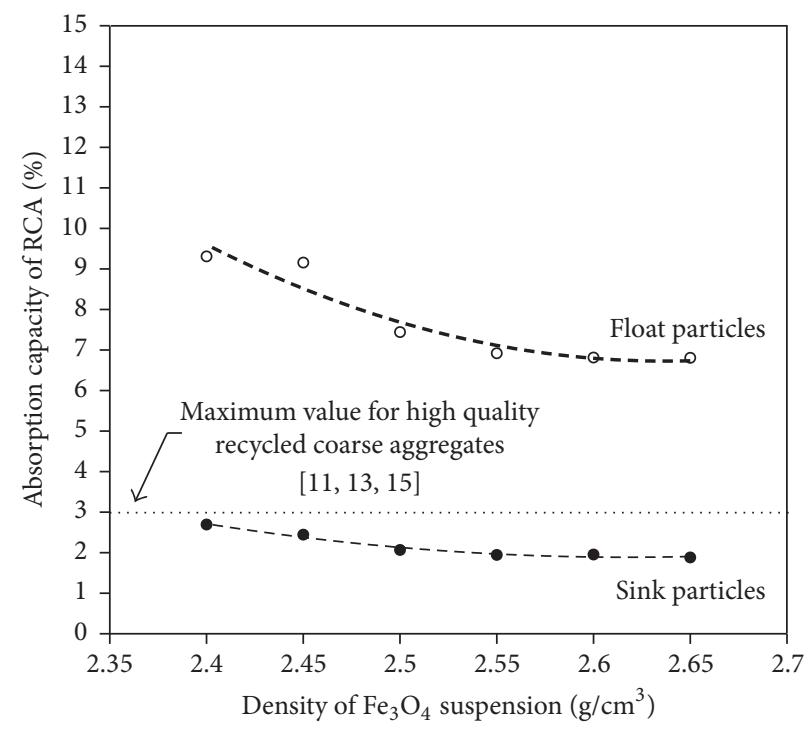

- Sink particles

- Float particles

- - - Best fit line for sink particles $\left[\mathrm{AC}_{\text {sink }}=17.36 \rho_{\mathrm{Fe}_{3} \mathrm{O}_{4}}{ }^{2}-90.89 \rho_{\mathrm{Fe}_{3} \mathrm{O}_{4}}+120.9\right.$, with $\left.R^{2}=0.96\right]$

- - - Best fit line for float particles

$\left[\mathrm{AC}_{\text {float }}=51.16 \rho_{\mathrm{Fe}_{3} \mathrm{O}_{4}}{ }^{2}-269.8 \rho_{\mathrm{Fe}_{3} \mathrm{O}_{4}}+362.5\right.$, with $\left.R^{2}=0.91\right]$

FIgURE 8: The variations of the absorption capacity of sink and float in the heavy medium separation process with a density of $\mathrm{Fe}_{3} \mathrm{O}_{4}$ suspension in the drum separator.

absorption capacity of sink products gradually decreases as the medium density increases, and the absorption capacity of sink products tends to converge into a certain values around $2.0 \%$. In this study, a quadratic equation was found to best express the relationship between the absorption capacity of sink products $\left(\alpha_{\text {sink }}\right)$ and the density of the $\mathrm{Fe}_{3} \mathrm{O}_{4}$ suspension $\left(\rho_{\mathrm{FE}_{3} \mathrm{O}_{4}}\right)$ as follows:

$$
\alpha_{\text {sink }}=17.36 \rho_{\mathrm{FE}_{3} \mathrm{O}_{4}}{ }^{2}-90.89 \rho_{\mathrm{FE}_{3} \mathrm{O}_{4}}+120.9 \text {, }
$$

$$
\text { with } R^{2}=0.96
$$

From (5), the minimum value of $\rho_{\mathrm{FE}_{3} \mathrm{O}_{4}}$ for complying with the minimum requirement of absorption capacity of RCA is 2.37 , which is equivalent to the value obtained from the minimum criterion for the OD density of RCA.

In the national standards and international recommendations, the quality of RCAs is evaluated based on the dualperformance criteria on oven-dry density and absorption capacity of RCAs. Therefore, it is of interest to investigate the relationship between the density and absorption capacity of finished sink particles from the HMS process in this study. Figure 9 shows the relationship between the OD density and the absorption capacity of sink and float particles in the HMS processes with various densities of $\mathrm{Fe}_{3} \mathrm{O}_{4}$ suspension. The dataset for the sink and float particles after the HEM processes is presented as solid and open squares, respectively, and a test result for the mixed CDW RCA before HMS is shown as solid circle in the figure. Consistent with the

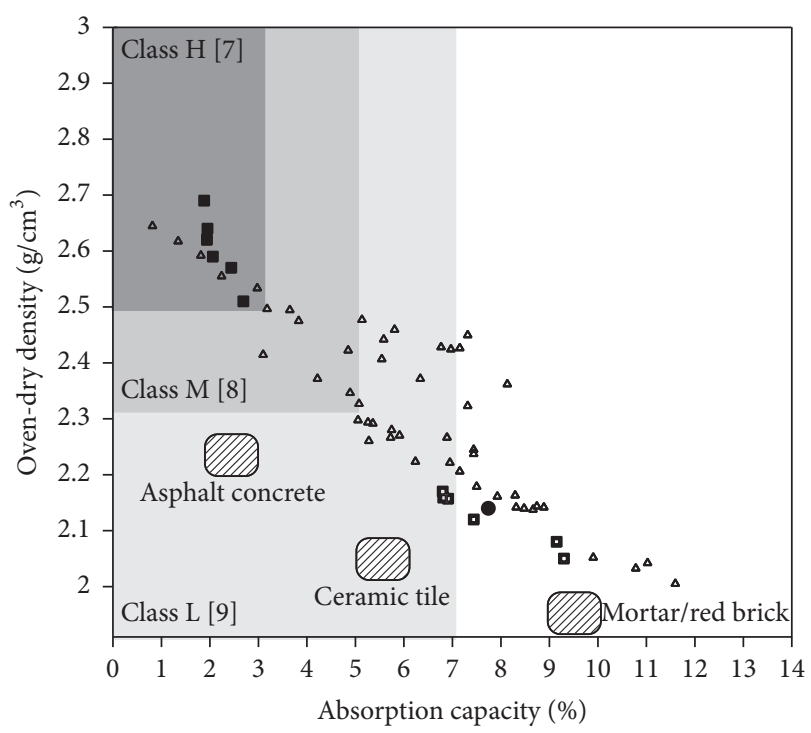

- RCA before the HMS process

- RCA after the HMS process (sink particles)

- Tailings after the HMS process (float particles)

$\Delta$ Data reported by Juan and Gutiérrez (2009)

FIGURE 9: The relationship between oven-dry density and absorption capacity of sink and float in the heavy media separation process and impurities in the mixed CDW RCAs in Korea.

observation from other researchers [1], there is a close correlation between OD density and absorption capacity of RCAs: higher OD density results in lower absorption capacity. The close correlation could be explained by the fact that both density and absorption capacity are affected by the amount of mortar attached to the surface of the RCAs [1, $17,26,27]$. It was observed that impurities in the mixed CDW RCA (e.g., plastic, asphalt concrete, ceramic, and red brick) are clearly separated from the high-quality RAC in the density and absorption curve. Therefore, it can be said that the prototype HMS system in this study is effective for classifying high-quality RCAs complying with the dualperformance criteria for structural concrete applications [39], even though the HMS process uses a single property (density) of input materials.

4.2. Physical Durability of Improved RCAs. Figure 10 is a plot representing the variations of mass losses of finished sink products after the Los Angeles test and sulfate ion test with a density of $\mathrm{Fe}_{3} \mathrm{O}_{4}$ suspension in the HMS process. Magnetite suspension with a density of $2.4 \mathrm{~g} / \mathrm{cm}^{3}$ resulted in the finished sink product with mass losses of $18.9 \%$ and $9.34 \%$ after the Los Angeles test and the sulfate ion test, respectively. The values are lower than the minimum criteria of RCAs for structural concrete applications [5, 7]. Furthermore, as medium density increases to $2.65 \mathrm{~g} / \mathrm{cm}^{3}$, the mass loss of the sink products gradually decreases to $12.1 \%$ and $4.33 \%$ after the Los Angeles test and sulfate ion test, respectively. The mass losses after both tests are as low as the values of natural granite in Korea. It is known that mass loss of aggregates from the Los Angeles 


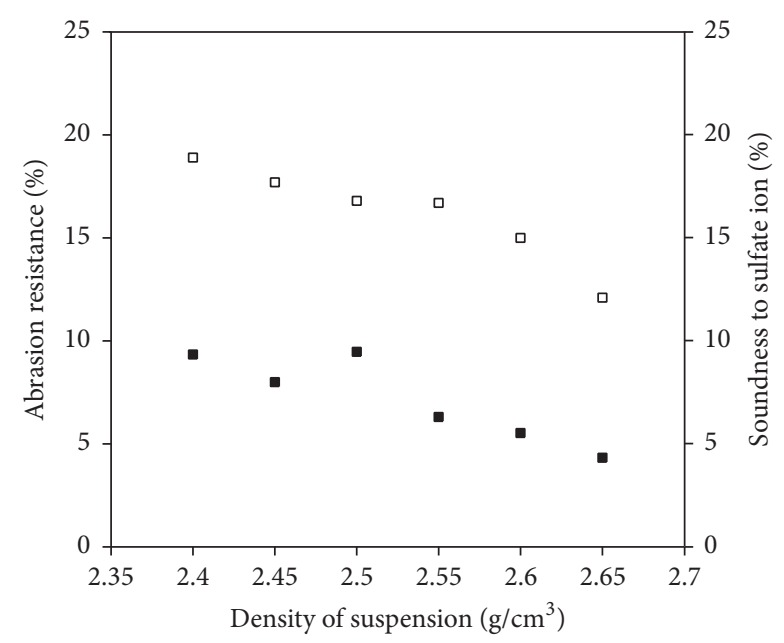

- Soundness to sulfate ion

$\square$ Abrasion resistance

FIGURE 10: Variation of sink rate with changing the density of the $\mathrm{Fe}_{3} \mathrm{O}_{4}$ suspension from 2.4 to $2.65 \mathrm{~g} / \mathrm{cm}^{3}$.

test indicates the abrasion resistance of aggregates [28]; the aggregates with lower mass loss are interpreted as having better resistance to breaking or damage during transportation and handling and as having improved mechanical properties (e.g., hardness, compressive strength, and tensile strength) [29]. In addition, the lower mass losses in the sulfate ion tests indicate sound aggregates that have good resistance to freezethaw weathering. Therefore, the HMS process is effective for improving the physical durability (i.e., abrasion resistance and soundness to weathering) of RCA to acceptable level for structural concrete applications.

4.3. Compressive Strength. Compressive strength of concrete is one of the most critical properties of structural concrete in construction applications. Figure 11 shows the compressive strengths of concrete cylinders made of RCAs before and after the HMS process with varying the density of magnetite suspension.

For the concrete cylinders made with the unprocessed RCA (mix 1), the compressive strength was reduced by about $30 \%$ compared to that of the reference cylinders at the same testing day. The 7-, 14-, and 28-day compressive strengths of concrete mix 1 were $17.1,22.3$, and $25.2 \mathrm{MPa}$, respectively. The reduced compressive strength is mainly due to the weak residual mortar layer and higher water absorption capacity of the aggregate $(7.74 \%$ in this study) [30, 31]. Moreover, the 28-day compressive strength of $25 \mathrm{MPa}$ is lower than the design compressive strength of $30 \mathrm{MPa}$. Therefore, the unprocessed RCA is not appropriate for structural concrete applications without special cares such as lowering the waterto-cement ratio and/or limiting the RCA fraction (the percentage of coarse aggregate replaced with unprocessed RCA) in a concrete mixture design. Note that the RCA fraction is limited to $20 \sim 45 \%$ of coarse aggregate for using the RCA to structural concrete applications in some national standards or international recommendations.
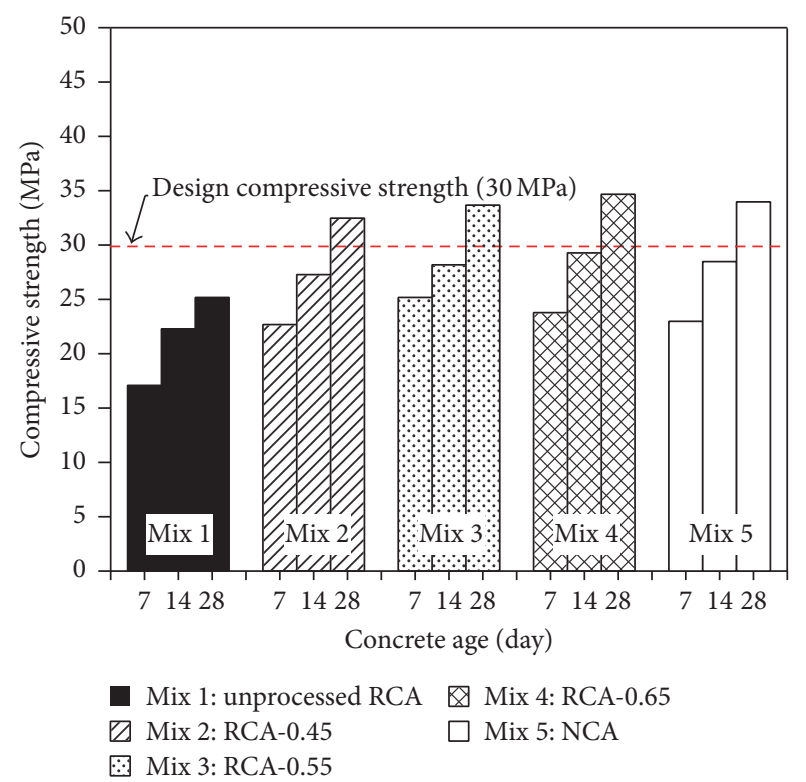

FIgURE 11: The variations of compressive strength of concrete cylinder made of different coarse aggregates with concrete age.

In contrast, the compressive strengths of concrete cylinders made with processed RCAs (RCA-2.45, RCA-2.55, and RCA-2.66) using the HMS system in this study are equivalent to those of NCA concrete. The 7-, 14-, and 28-day compressive strengths of concrete cylinders made with the RCA-2.45 were 22.7, 27.3, and 32.5 MPa, respectively, which are $90 \sim 95 \%$ of the reference cylinders. Furthermore, compressive strengths tend to increase as the magnetite medium density increases. For the concrete mix with the RCA-2.55, the 7-, 14-, and 28-day compressive strengths were 23.1, 28.2, and 33.7 MPa, respectively, which are about $95 \%$ of the reference cylinders. The compressive strengths further increases up to 96 99\% of the reference cylinders when using the RCA-2.65. The 28-day compressive strengths of the concrete cylinders with the three processed RCAs exceed the design compressive strength $(30 \mathrm{MPa})$. Therefore, it can be seen that the processed RCAs from the HMS systems are appropriate for structural concrete applications, if necessary with only minor alteration of water-to-cement ratio and/or higher RCA fraction than using the unprocessed RCA.

4.4. Production Rate of High-Quality RCA. Figure 12 shows the relationship between medium density in the HMS process and the production rate, which is defined in this study as the weight of the finished sink products over the total weight of input materials into the HMS process. The production rate gradually increases from $14 \%$ to $42 \%$ as the medium density decreases from $2.65 \mathrm{~g} / \mathrm{cm}^{3}$ to $2.4 \mathrm{~g} / \mathrm{cm}^{3}$. Among critical properties of RCA, it has been observed that density and absorption capacity are the most influential factors for the production of the high-quality RCAs in the construction applications. The minimum operating density in the HMS process that produces high-quality RCA complying with the dual-performance criteria $[3,5,7]$ on the density and 


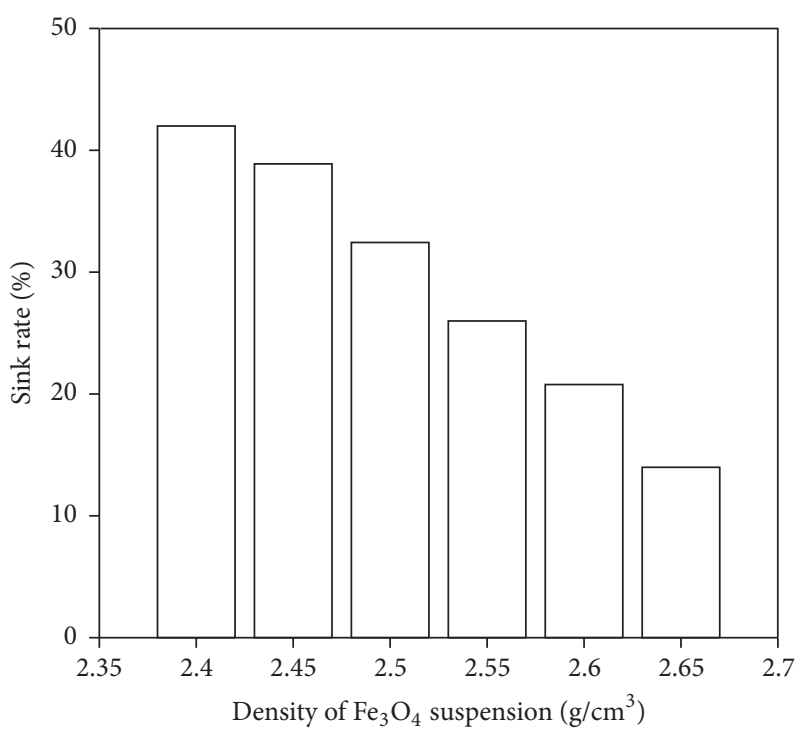

FIGURE 12: Variation of sink rate with changing the density of the $\mathrm{Fe}_{3} \mathrm{O}_{4}$ suspension from 2.4 to $2.65 \mathrm{~g} / \mathrm{cm}^{3}$.

absorption capacity is about $2.37 \mathrm{~g} / \mathrm{cm}^{3}$ based on (4) and (5). However, the actual operating medium density was decided to be about $2.45 \mathrm{~g} / \mathrm{cm}^{3}$ by taking into account some uncertainties during the HMS operation. The corresponding production rate to the medium density of $2.45 \mathrm{~g} / \mathrm{cm}^{3}$ is about $40 \%$, which simultaneously results in about $55 \%$ of tailings (i.e., float particles in the HMS process). The tailings could be used as subbase materials on the pavement construction without further recycling process.

\section{Conclusions}

In this study, a prototype heavy media separation (HMS) system that uses magnetite $\left(\mathrm{Fe}_{3} \mathrm{O}_{4}\right)$ suspension as pseudoheavy media was developed to upgrade the quality of mixed recycled coarse aggregates from construction and demolition waste (CDW RCA) in Korea. To verify the feasibility of the prototype system, a series of tests was performed to evaluate the properties of finished sink and float products from the HMS process with varying a density of $\mathrm{Fe}_{3} \mathrm{O}_{4}$ suspension from $2.65 \mathrm{~g} / \mathrm{cm}^{3}$ to $2.4 \mathrm{~g} / \mathrm{cm}^{3}$. Conclusions based on experiments in this study are drawn as follows:

(1) The prototype HMS system is composed of three main systems for heavy media separation process, magnetite recovering process, and waste water recycling process. Magnetite medium in rinsing water is recovered by two-stage magnetic separation process, which was effective for recycling most of the magnetite with a magnetite loss of about $100 \mathrm{~g}$ per $1 \mathrm{~m}^{3}$ of input materials. In addition, waste water was treated by a series of settling and filtering processes, and clean water is supplied to rinsing water recirculating in the circuit. As such, the prototype systems could effectively reduce the environmental impact of using recycled aggregates. A simple cost analysis estimates a processing cost of about 0.98 US $\$$ /ton to produce high-quality recycled coarse aggregates.

(2) As density of $\mathrm{Fe}_{3} \mathrm{O}_{4}$ suspension in a drum separator ranges between $2.65 \mathrm{~g} / \mathrm{cm}^{3}$ and $2.4 \mathrm{~g} / \mathrm{cm}^{3}$, critical properties of the sink products (OD density, absorption capacity, and physics durability) remain to have acceptable values for high-quality RCAs in structural concrete applications. With decreasing the medium density from $2.65 \mathrm{~g} / \mathrm{cm}^{3}$ and $2.4 \mathrm{~g} / \mathrm{cm}^{3}$, the OD density decreases from $2.69 \mathrm{~g} / \mathrm{cm}^{3}$ to $2.51 \mathrm{~g} / \mathrm{cm}^{3}$; the absorption capacity increases from $1.88 \%$ to $2.69 \%$; the mass losses from the Los Angeles test (or the sulfate ion test) increase from $9.34 \%$ to $18.9 \%$ (or from $4.33 \%$ to $12.1 \%)$.

(3) The compressive strengths of concrete cylinders made with processed RCAs (RCA-2.45, RCA-2.55, and RCA-2.66) using the prototype HMS system in this study are equivalent to those of NCA concrete. The 7-, 14-, and 28-day compressive strengths of concrete cylinders made with the RCA-2.45 were 22.7, 27.3, and $32.5 \mathrm{MPa}$, respectively, which are $90 \sim 95 \%$ of the reference cylinders.

(4) The production rate gradually increases from $14 \%$ to $42 \%$ as the medium density decreases from $2.65 \mathrm{~g} / \mathrm{cm}^{3}$ to $2.4 \mathrm{~g} / \mathrm{cm}^{3}$. In this study, the actual operating medium density was decided to be $2.45 \mathrm{~g} / \mathrm{cm}^{3}$ by taking into account some uncertainties during the HMS operation. The corresponding production rate is about $40 \%$, which simultaneously results in about $55 \%$ of tailings (i.e., float particles in the HMS process). The tailings could be used as subbase materials on the pavement construction without further recycling process.

\section{Competing Interests}

The authors declare that there is no conflict of interests regarding the publication of this manuscript.

\section{Acknowledgments}

This work was supported by Infrastructure and Transportation Technology Promotion Research Program funded by Ministry of Land, Infrastructure and Transport (Grant no. 15DRP-B066470-03) and supported by Ministry of Trade, Industry \& Energy (MOTIE) of the Republic of Korea (Grant no. 20151520100990).

\section{References}

[1] M. S. de Juan and P. A. Gutiérrez, "Study on the influence of attached mortar content on the properties of recycled concrete aggregate," Construction and Building Materials, vol. 23, no. 2, pp. 872-877, 2009.

[2] C. S. Poon, Z. H. Shui, and L. Lam, "Effect of microstructure of ITZ on compressive strength of concrete prepared with recycled 
aggregates," Construction and Building Materials, vol. 18, no. 6, pp. 461-468, 2004.

[3] RILEM Recommendation, "Specifications for concrete with recycled aggregates," Materials and Structures, vol. 27, no. 9, pp. 557-559, 1994.

[4] AS, Particle Density and Water Absorption of Aggregates (AS 1141.6.2-1996), Austrilian Standard, Sydney, Australia, 1996.

[5] KS F 2573, Recycled Aggregates for Concrete, Korean Industrial Standards, Seoul, Republic of Korea, 1999.

[6] DIN, "Aggregates for mortar and concrete-part 100: recycled aggregates," DIN 4226-100, Deutsches Institut für Normung, Berlin, Germany, 2002.

[7] Japanese Standards Association, "Japan Industrial StandardRecycled aggregate for concrete, Class H," JIS A 5021-2005, Japanese Standards Association, Tokyo, Japan, 2005.

[8] Japanese Standards Association, "Japan Industrial StandardRecycled aggregate for concrete, Class M,” JIS A 5022-2005, Japanese Standards Association, Tokyo, Japan, 2005.

[9] Japanese Standards Association, "Japan industrial standardrecycled aggregate for concrete, Class L," JIS A 5023-2005, Japanese Standards Association, Tokyo, Japan, 2005.

[10] S. Nagataki, A. Gokce, T. Saeki, and M. Hisada, "Assessment of recycling process induced damage sensitivity of recycled concrete aggregates," Cement and Concrete Research, vol. 34, no. 6, pp. 965-971, 2004.

[11] V. W. Y. Tam, C. M. Tam, and K. N. Le, "Removal of cement mortar remains from recycled aggregate using pre-soaking approaches," Resources, Conservation and Recycling, vol. 50, no. 1, pp. 82-101, 2007.

[12] H. Shima, H. Tateyashiki, R. Matsuhashi, and Y. Yoshida, "An advanced concrete recycling technology and its applicability assessment through input-output analysis," Journal of Advanced Concrete Technology, vol. 3, no. 1, pp. 53-67, 2005.

[13] L. Kiss and K. Schonert, "Liberation of two-component material by single particle compression and impact crushing," Aufbereitungs Technik, vol. 30, no. 5, pp. 223-230, 1980.

[14] E. Linß and A. Mueller, "High-performance sonic impulsesAn alternative method for processing of concrete," International Journal of Mineral Processing, vol. 74, pp. S199-S208, 2004.

[15] K. Bru, S. Touzé, F. Bourgeois, N. Lippiatt, and Y. Ménard, "Assessment of a microwave-assisted recycling process for the recovery of high-quality aggregates from concrete waste," International Journal of Mineral Processing, vol. 126, pp. 90-98, 2014.

[16] I. Vegas, K. Broos, P. Nielsen, O. Lambertz, and A. Lisbona, "Upgrading the quality of mixed recycled aggregates from construction and demolition waste by using near-infrared sorting technology," Construction and Building Materials, vol. 75, pp. 121-128, 2015.

[17] S. C. Angulo, P. M. Carrijo, A. D. Figueiredo, A. P. Chaves, and V. M. John, "On the classification of mixed construction and demolition waste aggregate by porosity and its impact on the mechanical performance of concrete," Materials and Structures, vol. 43, no. 4, pp. 519-528, 2010.

[18] C. Ulsen, H. Kahn, G. Hawlitschek, E. A. Masini, S. C. Angulo, and V. M. John, "Production of recycled sand from construction and demolition waste," Construction and Building Materials, vol. 40, pp. 1168-1173, 2013.

[19] ASTM, "Standard Test Method for lightweight particles in aggregate," ASTM C 1231998, American Society of Testing Materials, 1998.
[20] S. C. Angulo, C. Ulsen, P. M. Carrijo, V. M. John, and H. Kahn, "Characterization of Brazilian construction and demolition waste coarse recycled aggregate," in Proceedings of the International RILEM Conference on the Use of Recycled Materials in Building and Structures, RILEM Publications SARL, 2004.

[21] M.-G. Lee, K.-O. Kwon, G. Gayabazar, and H.-C. Kang, "Separation of recycled aggregates from waste concrete by heavy medium separation," in Proceedings of the in The 9th International Symposium on East Asian Resources Recycling Technology, Sendai, Japan, 2007.

[22] B. Klein, Rheology and Stability of Magnetite Dense Media, Department of Mining and Mineral Process Engineering, The University of British Columbia, 1992.

[23] ASTM, "Standard test method for specific gravity and absorption of coarse aggregate," ASTM C 127, Amerian Society of Testing Materials, 1993.

[24] ASTM, "Standard practice for making and curing concrete test specimen in the field," ASTM C 31-2012, Amerian Society of Testing Materials, 2012.

[25] ASTM, "Standard test method for compressive strength of cylindrical concrete specimen," ASTM C 39-2014, Amerian Society of Testing Materials, 2014.

[26] A. Abbas, G. Fathifazl, B. Fournier et al., "Quantification of the residual mortar content in recycled concrete aggregates by image analysis," Materials Characterization, vol. 60, no. 7, pp. 716-728, 2009.

[27] V. W. Y. Tam, X. F. Gao, C. M. Tam, and C. H. Chan, "New approach in measuring water absorption of recycled aggregates," Construction and Building Materials, vol. 22, no. 3, pp. 364-369, 2008.

[28] S. Mindness, J. F. Young, and D. Darwin, Concrete, Prentice Hall, New York, NY, USA, 2003.

[29] I. Ugur, S. Demirdag, and H. Yavuz, "Effect of rock properties on the Los Angeles abrasion and impact test characteristics of the aggregates," Materials Characterization, vol. 61, no. 1, pp. 90-96, 2010.

[30] M. Etxeberria, E. Vázquez, A. Marí, and M. Barra, "Influence of amount of recycled coarse aggregates and production process on properties of recycled aggregate concrete," Cement and Concrete Research, vol. 37, no. 5, pp. 735-742, 2007.

[31] J. Xiao, J. Li, and C. Zhang, "Mechanical properties of recycled aggregate concrete under uniaxial loading," Cement and Concrete Research, vol. 35, no. 6, pp. 1187-1194, 2005. 

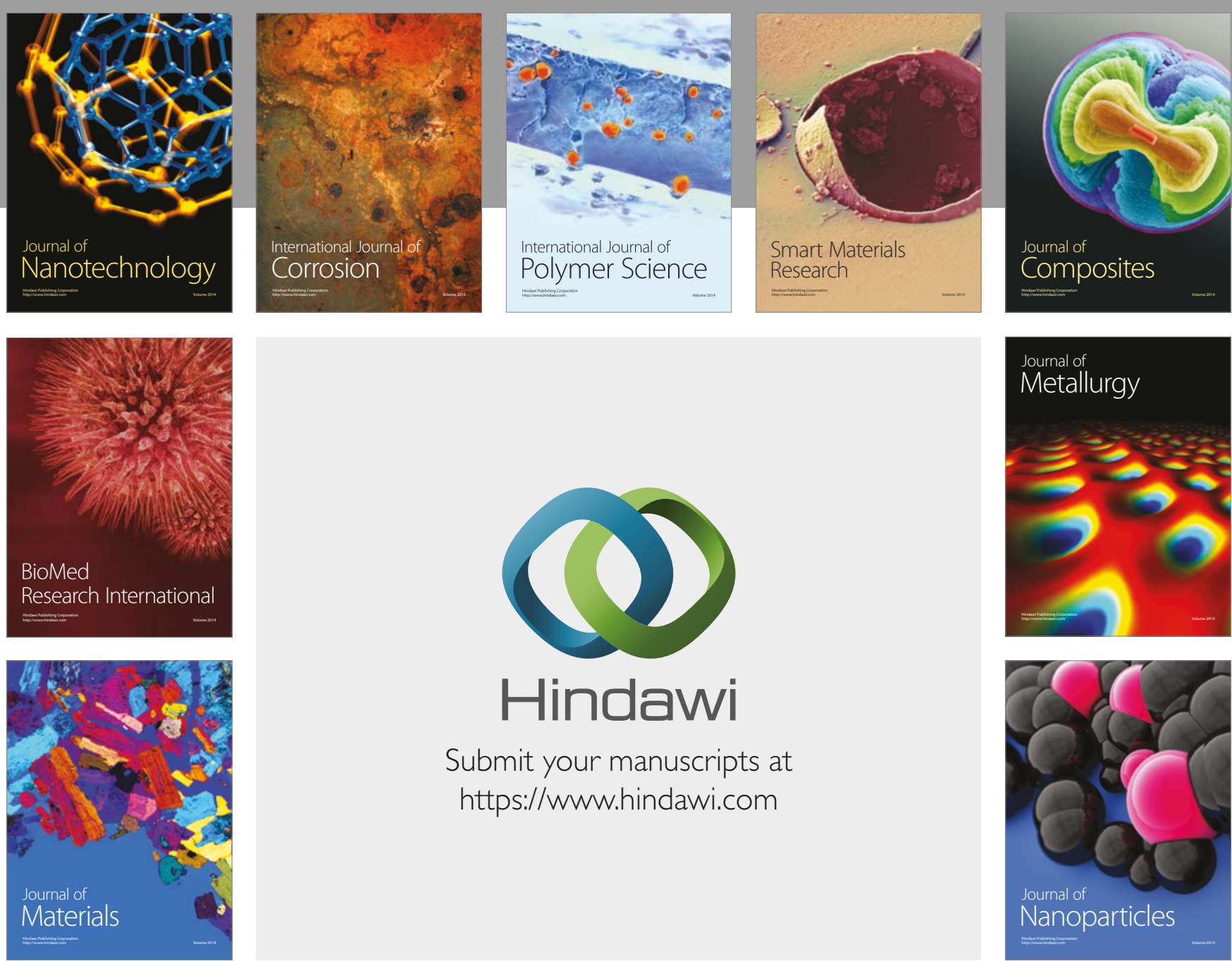

\section{Hindawi}

Submit your manuscripts at

https://www.hindawi.com
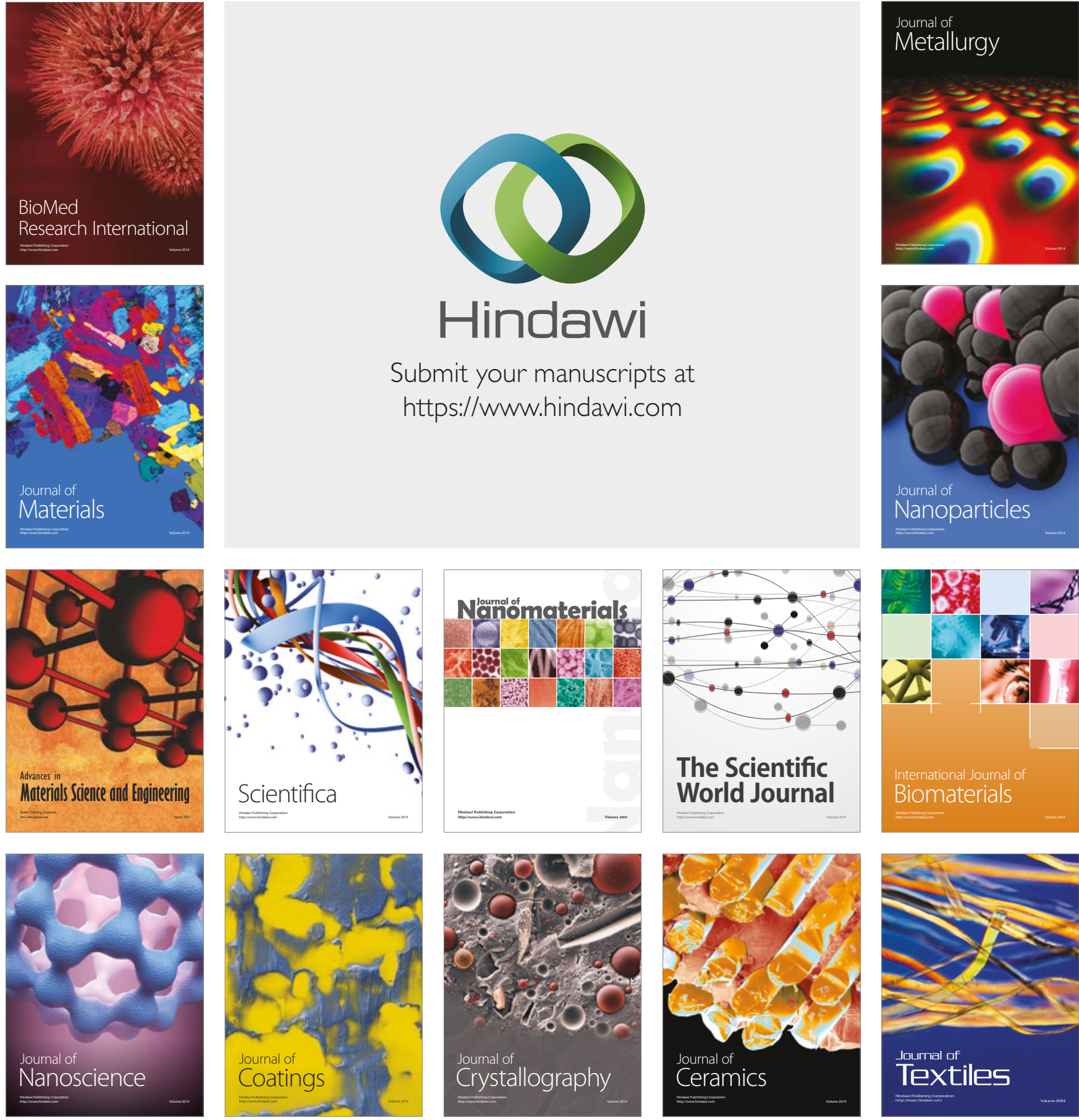

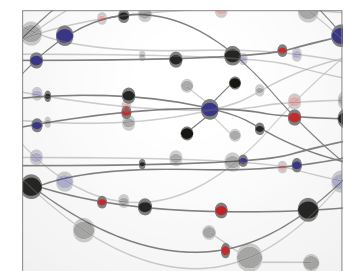

The Scientific World Journal
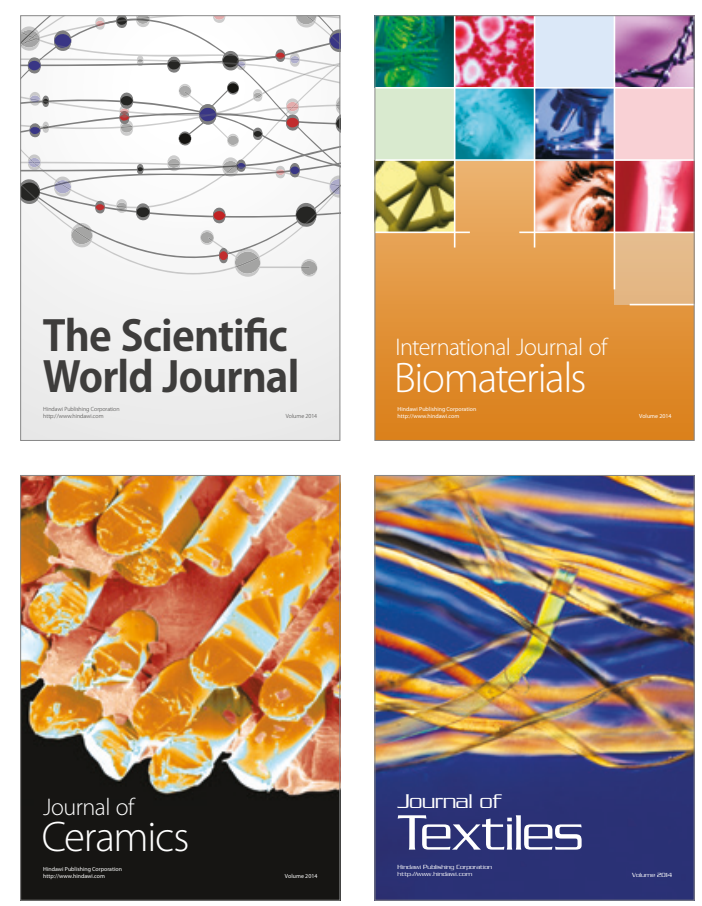